\title{
Moderators of occupational pressure in female health professionals-Individual differences and coping skills
}

\author{
Siew Yim Loh", Kia Fatt Quek \\ Faculty of Medicine, University of Malaya, Kuala Lumpur, Malaysia; 'Corresponding Author: syloh@um.edu.my
}

Received 8 July 2013; revised 8 August 2013; accepted 8 September 2013

Copyright (C) 2013 Siew Yim Loh, Kia Fatt Quek. This is an open access article distributed under the Creative Commons Attribution License, which permits unrestricted use, distribution, and reproduction in any medium, provided the original work is properly cited.

\begin{abstract}
Individual differences and coping skills have influential impacts on stress process by influencing the eventual outcomes of the stressors, contributing to either wellbeing, or illness and negative experiences. The aim of this paper is to explore the individual differences and coping strategies of a cohort of women with health professionals' occupational pressure. This is a crosssectional survey, informed by the transactional model of stress and coping framework, and carried out on women health professionals $(n=203)$ from the Kuala Lumpur Hospital. Multiple regressions were conducted to examine the potential moderators of stress. Women Health Professionals reported stress with six out of eight organizational sources of pressure, with relationship being a key stressor. Their individual differences (mean + SD) were characterised by low drive $(7.6+1.9-8.2+2.0)$, low personal influence $(10.8+2.0$ to $11.7+2.3)$, moderate control $(13.4+3.4$ to $16.3+2.4)$, and high impatience behaviour $(19.1+3.8$ to $20.4+3.3)$. With Coping strategy, the Life-work-balance coping is a significant positive predictor for five out of the nine outcomes of occupational pressure [state of mind $(p<0.001)$, level of resilience $(p=0.01)$, level of confidence $(p=0.003)$, physical symptoms $(p=0.001)$ and energy level $(p<0.001)]$. The findings show relationship as a key stressor, with a less favourable pattern of individualdifferences and an over-reliance on lifework balance coping. Female health professionals, stressed at work, have an undesirable profile of individual difference and a coping strategies, suggestive of attempts to balance the demands of their dual work role. The increasing female into
\end{abstract}

the workforce, warrants more research to inform stress management guideline to ameliorate stress amongst those vulnerable workers. Future studies to examine individual differences of these female-dominated professions across health setting are needed to better inform the pressureat-work issues for the increasing Asian women health professionals.

Keywords: Occupational Pressure; Women; Individual Differences; Coping

\section{INTRODUCTION}

Stress at work has been the number one reason behind sickness from work, with more than two thirds of people suffering from work-related stress [1]. Stress literature showed that specific, enduring work-related stressful experiences contribute to depression [2,3], predicted as one of the three leading causes of burden of disease worldwide [4-6]. Individual differences and variability and/or reactivity may be an appropriate concept to understand and ameliorate work pressure and reduce its debilitating effects [7]. The study uses the Transactional Model of Stress and Coping framework to understand the multi-factorial causes of work stress. Stress is mediated by people's appraisal of the stressor and, by the social-cultural resources at their disposal $[7,8]$. Significant differences exist in terms of physical and psychological wellbeing amongst the male and female workers $[9,10]$. Comic et al. [11] explain that role demands such as that of being wife, mother and professional provoke role conflicts for female workers. In order to help female health professionals manage work stress, an understanding of their social and occupational role and the individual differences is fundamental. These individual differences (i.e. type-behaviour, level of patience, perception of control and personal-influence) and coping strategies (i.e. prob- 
lem-focus and life-work balance) are influential in the stress process. These explanatory variables should be examined to inform individuals about their self-management de-stressing skills. There are relatively less paper describing these variables and/or how they impacted the stress relationships, or what their key features are within a certain organizational climate. This paper examines the four variables within the individual differences, two coping strategies and social support of the female health professional, and its relationship with the nine measures of effect of occupational pressure.

\section{METHODOLOGY}

\subsection{Study Design and Sampling}

Respondents for this survey were selected using cluster sampling of all women professionals from the seven health care professions in Kuala Lumpur Hospital (KLH), a tertiary referral, government hospital under the Malaysian Ministry of Health. There were 233 females out of the total 331 health professionals from the seven disciplines, which make up about $73 \%$ of the health professions workforce during the time this audit was carried out. KLH is considered to be one of the biggest hospitals in Asia, with 2502 beds and 7000 workers with almost
100 professions in various disciplines.

\subsection{The Survey Instrument}

The Pressure Management Inventory (PMI), a second-generation tool developed from the Occupational Stress Inventory is a copyrighted tool for measuring pressure at work [12]. It is based on a transactional model of the stressor-strain relationship that identifies three components of stress-sources, effect and component of relationship (i.e. individual differences and coping strategies). The 145 items PMI requires about 20 minutes to complete, and covers all aspects of the pressure-strain relationship (Figure 1). In the PMI, the eight sources of pressure interact with the moderators (i.e. type of behaviour, control, coping and support), with the eventual occupational outcomes. The individual differences includes: 1) Type A Behaviour, as measured by a) drive - to succeed and achieve results, and b) patienceimpatience - pace of life and ability to cope with the need for urgency); 2) Influence and control, as measured by a) control - the extend one feel able to control events) and b) personal Influence - how much influence one has over work and are able to exercise discretion in one's job.

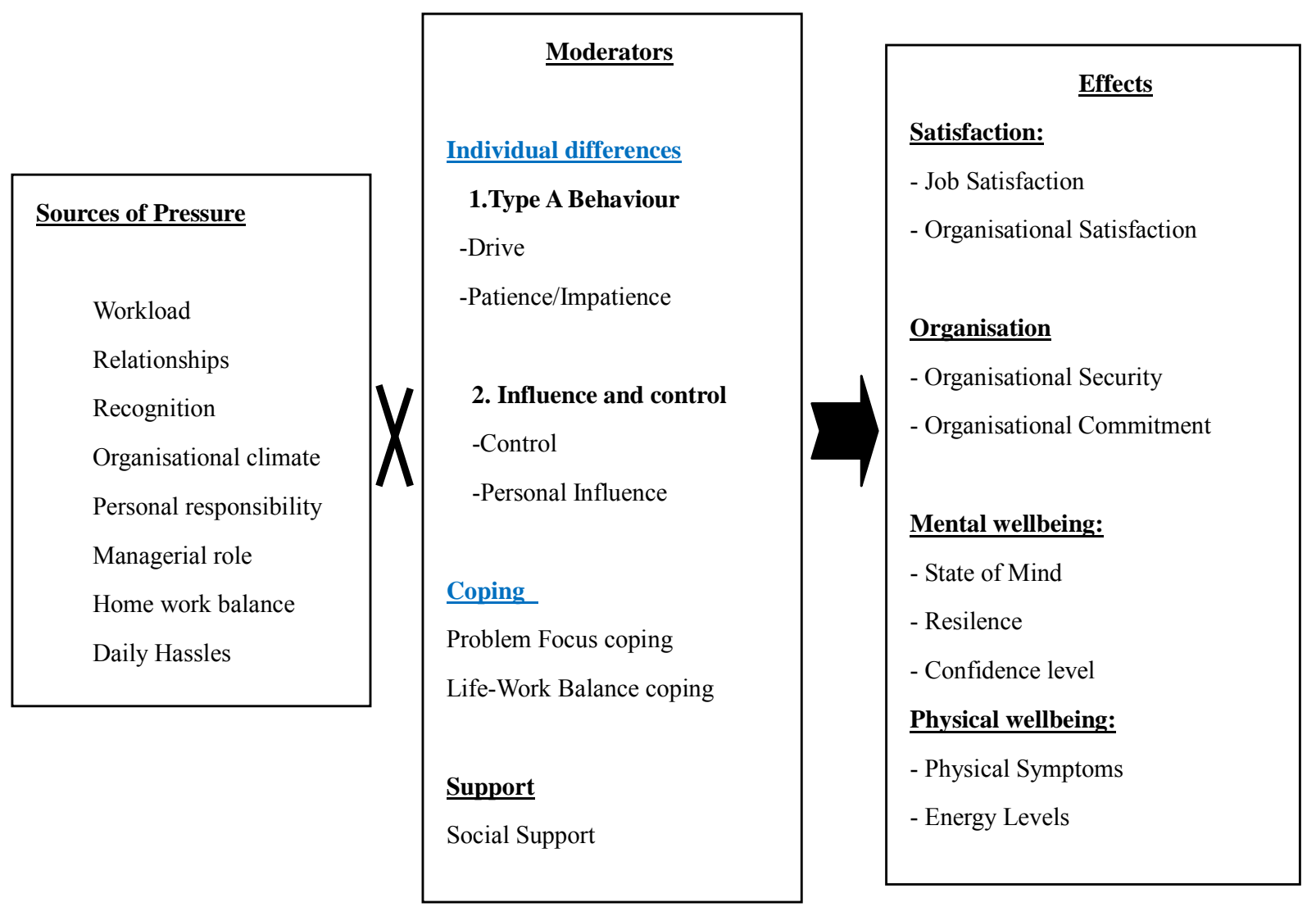

Figure 1. The Pressure Management Inventory: transactional view of the processes; Adapted from Resource Systems, Harrogate, UK (1996). 
The Coping Strategies consist of two types: 1) Problem Focus coping - the extend one is able to plan ahead and manage time to deal with problems) and 2) LifeWork Balance coping - the extend one is able to separate home from work and not let things gets to oneself). Social Support refers to the help one gets by discussing problems or situations with other people. The instrument have been validated and showed good internal consistencies (alpha < 0.7) for most subscales. The test-retest correlation coefficients were significant at the level of $\mathrm{p}<$ 0.001 for almost all scale. The ICC coefficients were also high $(>0.7)$ particularly for Pressure, Health and Coping Scales (Loh, 2004).

\subsection{Data Collection}

Upon ethical approval from the Kuala Lumpur Hospital Ethics Committee, briefings were conducted on the key representatives of seven health disciplines (Occupational Therapy, Physiotherapy, Medical Laboratory Technology, Medical Dispenser, Radiotherapy and Radiography and Counselling, and Social work), to explain the purpose of the study. Confirmation of the where about of the health professionals were checked with the census obtained from the human resource office of each individual department. From the list, the female health professionals were identified and those servicing outside the Hospital premise were excluded to ensure the pressure was within the organisation. The women were informed of the study and were given the consent form. Those who signed the consent form were followed up with the PMI questionnaire.

\subsection{Data Analyses}

Data analysis was performed using the SPSS version 16 (SPSS Inc., Ill., Chicago, USA. Statistical tests such as descriptive statistic, analyses of variance, independent $t$ tests, correlations and analyses of variance (ANOVA) were used. Multiple linear regressions were performed to examine the variables on the individual differences as predictors of the effect of occupational pressure as (Figure 1).

\section{RESULTS}

\subsection{Psychometrics of PMI}

All items on the stressors, and outcome were found to be statistically significant. In the influential item variables variable, only individual differences $(\mathrm{r}=0.12, \mathrm{p}>$ 0.05) was not found to be significant. The Cronbach Alpha (internal consistencies) of 0.7 and above was noted for most scales (except for job satisfaction, $\boldsymbol{\alpha}=0.61$, type A drive, $\alpha=0.62$; patience-impatience, $\alpha=0.21$; social support, $\alpha=0.59$ ) suggesting the reliability of most of the scales are acceptable. This supports most subscales met the required coefficient of 0.7 and above [13]. Items such as social support (0.59), type A (0.62), patient impatience (0.21) and control (0.64) were all below 0.7 , and thus have to be interpreted with caution. The panel of six psychiatrists provided the consensus that the PMI has face validity. However, in terms of content, the panel concurred that the PMI may pose some difficulty for the average Malaysian because of some of the ambiguous and difficult wordings in the PMI. This was the reason why PMI was supplemented with a Malay version. In addition, in term of appropriateness for measuring occupational pressure of female, the panel also highlighted some women-specific health-related issues and home-environment issues that were not highlighted in the PMI. However, this was not included in this study where PMI was used.

\subsection{Socio-Demographic Characteristic of Female Health Professionals}

Table 1 showed the response rate of the various professions this study, while Table 2 showed the demographic background of the women. The seven professions comprising of 330 workers, out of which, $72 \%$ are female workers. The response rate for this survey was $84 \%$ (Table 1). Non respondents also included those who were on leave and those servicing outside the HKL premise. About $68 \%$ were within the age range of 20 - 39 years old. Almost $80 \%$ were assigned to the lowest grade -basic entry grade (U8) within the profession. Thus, only $20 \%$ are holding the higher managerial tasks of overseeing these $80 \%$ workforce. In terms of ethnic group, the majority $(82 \%)$ were Malays followed by the Chinese, Indians, Sikh, Eurasians and Others. About 60\% were married and about half of these married women have children. Overall, only $27 \%$ claimed to engage in some form of regular exercise at least three days a week.

\subsection{The Occupational Pressure of Women Health Professionals}

Table 3 shows the mean scores for all the five groupings of profession. Three stressors-relationship, personal responsibility and organizational climate were rated consistently as the highest stressors across these professions. Standardization of mean-score of the stresssor over the number of items within the scale, were computed to describe the ranking of stressors within the seven professions. The top three work stressors within the five clusters of professionals were presented in Table 3. Three stressors (relationship, personal responsibility and organizational climate) were rated consistently high across the various professions. There were significant differences in five of the eight sources of pressure, across 
Table 1. Response rate of the various professions.

\begin{tabular}{cccccc}
\hline Profession & Total (Male \& female) & Female (n) & \% female in profession & $\begin{array}{c}\text { Eligible female } \\
\text { respondents }\end{array}$ & $\begin{array}{c}\text { \% Response rate } \\
\text { within profession }\end{array}$ \\
\hline Medical dispensers & 63 & 46 & $73 \%$ & 43 & $94 \%$ \\
Medical technologists & 109 & 70 & $64 \%$ & 66 & $94 \%$ \\
Radiotherapist & 42 & 27 & $64 \%$ & 27 & $100 \%$ \\
Radiographer diagnostic & 60 & 43 & $72 \%$ & 25 & $58 \%$ \\
Physiotherapists & 38 & 35 & $92 \%$ & 28 & $80 \%$ \\
Occupational/ Social & 18 & 15 & $73 \%$ & 14 & $93 \%$ \\
Welfare/Counsellors & $\mathbf{3 3 0}$ & $\mathbf{2 3 8}$ & & $\mathbf{2 0 3}$ & Overall response \\
Total & & & & rate 84\%) \\
\hline
\end{tabular}

Table 2. Background of Female health professionals $(n=203)$.

\begin{tabular}{|c|c|c|c|}
\hline & $\mathrm{N}=203$ & $\mathrm{n}$ & $\%$ \\
\hline \multirow{4}{*}{ Age Group } & $20-29$ & 91 & 44.8 \\
\hline & $30-39$ & 50 & 24.6 \\
\hline & $40-49$ & 52 & 25.6 \\
\hline & $50-59$ & 10 & 4.9 \\
\hline \multirow{4}{*}{ Job Grade } & U5 (Supervisor) & 7 & 3.5 \\
\hline & U6 (Section supervisor) & 7 & 3.4 \\
\hline & U7 (senior therapist) & 28 & 13.8 \\
\hline & U8 (junior therapist) & 160 & 78.8 \\
\hline \multirow{4}{*}{ Ethnic } & Malay & 147 & 72.4 \\
\hline & Chinese & 36 & 17.7 \\
\hline & Indian & 14 & 6.9 \\
\hline & Others & 6 & 3.0 \\
\hline \multirow{3}{*}{ Marital status } & Married & 118 & 58.1 \\
\hline & Single & 81 & 39.9 \\
\hline & Others & 4 & 2.0 \\
\hline \multirow{3}{*}{ No of Children } & $<12$ yrs only & 49 & 24.1 \\
\hline & $>12$ yrs only & 19 & 9.4 \\
\hline & Both age groups & 27 & 13.3 \\
\hline \multirow{2}{*}{ Exercise Status } & Yes & 55 & 27.1 \\
\hline & No & 148 & 72.9 \\
\hline
\end{tabular}

the profession. These were recognition $(p<0.001)$, organisational climate $(p=0.001)$, personal responsibility $(p=0.002)$, managerial role $(p=0.016)$ and daily hassle $(p=0.007)$. The Occupational therapists, social welfare and counsellor cluster reported the highest significant pressure from recognition, personal responsibility and managerial role, whilst the radiographers reported the highest significant pressure from organisational climate and daily hassles. Post hoc test showed that the radiographer-therapy group had significantly higher stressors compared to the medical laboratory technologists for recognition $(\mathrm{p}<0.001)$, and daily hassles $(\mathrm{p}=0.007)$, and compared to medical dispenser for stressor with or- ganisation climate $(\mathrm{p}=0.002)$.

In terms of demographics, between the exercisers $(n=$ $54)$ and non-exercisers $(n=148)$ - the sources of pressure were significantly lower for exercisers compared to non exercisers for all sources except for relationship and personal responsibility. Between the married $(\mathrm{n}=118)$ and single $(\mathrm{n}=85)$ - sources of pressure were significantly different only for personal responsibility $(\mathrm{p}=$ $0.043)$ and for home-work balance $(p=0.004)$. There were, however, no significant difference between those with children and those without children.

\subsection{Individual Differences}

Table 4 showed the differences in the mean-scores of individual differences and coping strategies of the five professions. The differences across professions was significant on job-control $(p=0.001)$, a key item of individual differences. The Occupational therapist, counsellor and social worker cluster recorded the highest mean score for job control $(16.3+2.4)$ whilst the medical dispensers $(13.4+3.4)$ and radiographer and radiotherapist $(14.7 \pm 3.0)$ had the lowest scores for job control.

Among the demographic variables, job grades, age and marital status were found to be statistically significant in the effect of occupational pressure. Between the lower and higher job grades, there were higher ratings for those with higher job-grade on items like personal influence $(p$ $=0.013)$ and life work balance $(p=0.03)$. Between age-groups, there were significant difference in the level of impatience $(p=0.013)$ and problem focus copings ( $p$ $=0.034$ ). The younger group displayed higher scores on impatience and lower scores on problem-focus copings. With marital status, there were significant difference in drive $(p=0.016)$, personal influence $(p=0.001)$ and problem focus coping $(p=0.03)$. The means scores showed that the divorcee had higher control, personal influence and problem focus coping compared to either the married or the single group. Post hoc analysis showed personal influence to be statistically significant amongst the divorcees compared to single women $(\mathrm{p}=$ $0.003)$. 
Table 3. Occupational stressor of female health professionals $(n=203)$ (Mean and SD).

\begin{tabular}{|c|c|c|c|c|c|c|}
\hline \multirow[b]{2}{*}{ STRESSORS } & \multicolumn{5}{|c|}{ Individual cluster of Professions } & \multirow{2}{*}{$\begin{array}{c}\text { Sig }^{*} \\
\text { ANOVA }\end{array}$} \\
\hline & $\begin{array}{l}\text { MLT }(n=66) \\
{[\text { Mean } \pm \text { SD }]}\end{array}$ & $\begin{array}{c}\mathrm{RG} / \mathrm{RT}(\mathrm{n}=53) \\
{[\mathrm{Mean} \pm \mathrm{SD}]}\end{array}$ & $\begin{array}{l}\mathrm{MD}(\mathrm{n}=43) \\
{[\mathrm{Mean} \pm \mathrm{SD}]}\end{array}$ & $\begin{array}{c}\text { PT }(n=26) \\
{[\text { Mean } \pm \text { SD }]}\end{array}$ & $\begin{array}{c}\text { OT, SW \& C }(\mathrm{n}=15) \\
{[\text { Mean } \pm \mathrm{SD}]}\end{array}$ & \\
\hline Workload & $17.8 \pm 5.1$ & $19.3 \pm 5.3$ & $17.3 \pm 6.2$ & $19.2 \pm 6.2$ & $18.9 \pm 6.8$ & 0.360 \\
\hline Relationship & $29.0 \pm 7.5$ & $32.1 \pm 6.1$ & $30.2 \pm 7.7$ & $28.7 \pm 7.1$ & $29.5 \pm 8.7$ & $0.001^{*}$ \\
\hline Recognition & $11.6 \pm 3.8$ & $14.4 \pm 4.0$ & $12.7 \pm 3.2$ & $14.3 \pm 2.9$ & $15.2 \pm 4.1$ & $0.002^{*}$ \\
\hline Personal Responsibility & $13.5+3.8$ & $16.0 \pm 3.7$ & $13.4 \pm 5.2$ & $15.4 \pm 4.1$ & $16.3 \pm 4.0$ & $0.016^{*}$ \\
\hline Managerial role & $7.0+2.8$ & $8.4 \pm 3.8$ & $7.2 \pm 4.1$ & $9.1 \pm 3.2$ & $9.3 \pm 4.5$ & $0.001^{*}$ \\
\hline Organisation Climate & $13.6+4.0$ & $15.8 \pm 3.3$ & $13.0 \pm 3.8$ & $13.6 \pm 3.3$ & $15.7 \pm 3.6$ & $0.016^{*}$ \\
\hline Home-work balance & $16.3+5.8$ & $17.8 \pm 5.1$ & $17.4 \pm 6.2$ & $18.4 \pm 5.6$ & $18.3 \pm 5.8$ & 0.458 \\
\hline Daily Hassles & $11.8+3.0$ & $13.7 \pm 3.0$ & $12.2 \pm 3.0$ & $13.4 \pm 3.1$ & $12.3 \pm 3.4$ & $0.007^{*}$ \\
\hline
\end{tabular}

MLT = Medical technologist; RG-RT = radiographers-radiotherapists; MD = medical dispensers; PT = physiotherapists; OT, SW \& C + Occupational therapists, social workers and counsellor; ${ }^{*}=$ significant.

Table 4. Descriptive influential item variables variables (Mean and SD) across the professions.

\begin{tabular}{|c|c|c|c|c|c|c|c|}
\hline \multirow[b]{2}{*}{$\begin{array}{l}\text { Influential item } \\
\text { variables }\end{array}$} & \multirow{2}{*}{$\begin{array}{c}\text { TOTAL } \\
(\mathrm{n}=203) \\
\text { Mean } \pm \text { SD }\end{array}$} & \multicolumn{5}{|c|}{ Individual cluster of Professions } & \multirow{2}{*}{$\frac{\text { Sig }^{*}}{\begin{array}{c}\text { ANOVA } \\
\text { (bet' groups) }\end{array}}$} \\
\hline & & $\begin{array}{c}\text { MLT }(n=66) \\
\text { Mean } \pm \text { SD }\end{array}$ & $\begin{array}{l}\text { RG \& RT }(\mathrm{n}=53) \\
\quad \text { Mean } \pm \text { SD }\end{array}$ & $\begin{array}{c}\mathrm{MD}(\mathrm{n}=43) \\
\text { Mean } \pm \mathrm{SD}\end{array}$ & $\begin{array}{l}\mathrm{PT}(\mathrm{n}=26) \\
\text { Mean } \pm \mathrm{SD}\end{array}$ & $\begin{array}{c}\text { OT, SW \& C } \\
(\mathrm{n}=15) \\
\text { Mean } \pm \text { SD }\end{array}$ & \\
\hline \multicolumn{8}{|l|}{ Individual differences } \\
\hline Type A Drive & $7.9 \pm 2.2$ & $8.2 \pm 2.0$ & $8.0 \pm 2.3$ & $7.6 \pm 1.9$ & $8.0 \pm 1.8$ & $7.8 \pm 3.3$ & 0.64 \\
\hline Patience-impatience & $19.6 \pm 3.4$ & $19.3 \pm 3.2$ & $19.1 \pm 3.8$ & $20.2 \pm 3.5$ & $20.4 \pm 3.3$ & $19.7 \pm 2.3$ & 0.35 \\
\hline Control $^{*}$ & $14.8 \pm 3.1$ & $15.3 \pm 2.7$ & $14.7 \pm 3.0$ & $13.4 \pm 3.4$ & $15.3 \pm 3.2$ & $16.3 \pm 2.4$ & $0.01^{*}$ \\
\hline Personal Influence & $11.1 \pm 1.9$ & $10.8 \pm 2.0$ & $11.2 \pm 1.8$ & $11.1 \pm 2.0$ & $11.3 \pm 1.8$ & $11.7 \pm 2.3$ & 0.58 \\
\hline \multicolumn{8}{|l|}{ Coping scales } \\
\hline Problem focus & $24.7 \pm 3.8$ & $24.8 \pm 4.0$ & $24.4 \pm 3.1$ & $24.1 \pm 3.9$ & $25.3 \pm 4.1$ & $25.7 \pm 4.9$ & 0.54 \\
\hline Lifework balance & $17.6 \pm 3.1$ & $17.4 \pm 3.0$ & $18.1 \pm 2.9$ & $17.1 \pm 3.3$ & $17.7 \pm 3.3$ & $17.7 \pm 2.8$ & 0.65 \\
\hline Social support & $11.9 \pm 2.5$ & $11.7 \pm 2.3$ & $12.1 \pm 2.0$ & $11.4 \pm 3.0$ & $12.3 \pm 2.0$ & $12.7 \pm 2.9$ & 0.32 \\
\hline
\end{tabular}

MLT = Medical technologist; RG \& RT = radiographers-radiotherapists; MD = medical dispensers; PT = physiotherapists; OT, SW \& C + Occupational therapists, social workers and counsellor ${ }^{*}=$ significant.

\section{THE ROLE OF INDIVIDUAL DIFFERENCES AND COPING STRATEGIES ON THE EFFECT OF WORK PRESSURE}

Table 5 showed result of multiple linear regression analyses on variables conducted on each of the nine effects of pressure. Overall, the variables account for $20 \%$ $-30 \%$ variation of the combined variables for each of the eight effects of pressure. Only the "physical symptoms" variable have the lowest (14\%) variation accounted for the outcome.

Of the four individual differences items, the item "Control" was found to be statistically significant and has a positive relationship with three out of nine effect of occupational pressure [i.e. organisational satisfaction, organisational security, and energy level $(\mathrm{p}<0.007)]$. The variable, "impatience" was significantly and negatively associated with job satisfaction, state of mind and level of confidence $(\mathrm{p}<0.007)$.
Across the three coping scales, the 'life-work-balance' coping was found to be an key factor for four out of the nine outcomes of occupational pressure amongst these female cohort. This item was a significant predictor of state-of-mind $(B=0.326, \mathrm{p}<0.001)$, level of confidence $(B=0.226, \mathrm{p}=0.003)$, physical symptoms $(B=0.259, \mathrm{p}$ $=0.001)$ and energy level $(B=0.374, \mathrm{p}<0.001)$. The other coping style, the problem-focus coping was a significant predictor of level of resilience $(B=0.356, \mathrm{p}<$ $0.001)$, and of organisational commitment $(B=0.193, \mathrm{p}$ $<0.001)$. Personal influence was the only positive significant predictor for organisational commitment $(\mathrm{B}=$ $0.32, \mathrm{p}=0.002$ ).

\section{DISCUSSIONS}

The survey unravelled the occupational pressure of female health professionals (mid level positions) in a large medical-model hospital-based organisation. Two out of the five groups of health professions surveyed 
Table 5. Unstandardised (B) and standardised $(\beta)$ regression coefficients: explanatory and effect.

\begin{tabular}{|c|c|c|c|c|c|c|c|}
\hline \multirow{2}{*}{$\begin{array}{l}\text { Independent/Explanatory } \\
\text { variables/(IV) }\end{array}$} & \multicolumn{3}{|c|}{ Unstandardized Coefficients } & & \multirow{2}{*}{$\mathbf{t}$} & \multirow{2}{*}{ P value ${ }^{* *}$} & \multirow{2}{*}{ Effect of Pressure DV } \\
\hline & $\mathrm{B}$ & $95 \% \mathrm{CI}$ for $\mathrm{B}$ & SE & & & & \\
\hline Impatience & -0.203 & $-0.35 ;-0.02$ & 0.087 & -0.159 & -2.31 & 0.0017 & Job satisfaction $\mathrm{R}^{2}=0.240$ \\
\hline Control & 0.572 & $0.35 ; 0.76$ & 0.106 & 0.372 & 5.41 & 0.001 & $\begin{array}{l}\text { Organisation Satisfaction } \\
\qquad \mathrm{R}^{2}=0.22\end{array}$ \\
\hline Control & 0.390 & $0.26 ; 0.53$ & 0.068 & 0.374 & 5.76 & 0.000 & $\begin{array}{c}\text { Organisation Security } \\
\mathrm{R}^{2}=0.30\end{array}$ \\
\hline Personal influence & 0.19 & $0.07 ; 0.31$ & 0.51 & 0.06 & 3.32 & 0.001 & $\begin{array}{l}\text { Organisation Commitment } \\
\qquad \mathrm{R}^{2}=0.24\end{array}$ \\
\hline Problem focus Coping & 0.32 & $0.12 ; 0.51$ & 0.10 & 0.22 & 3.17 & 0.002 & \\
\hline Impatience & -0.366 & $-0.54 ;-0.21$ & 0.086 & -0.284 & -4.25 & 0.000 & State of Mind \\
\hline Life-work balance Coping & 0.464 & $0.26 ; 0.66$ & 0.104 & 0.326 & 4.46 & 0.000 & $\mathrm{R}^{2}=0.28$ \\
\hline Problem focus Coping & 0.252 & $0.16 ; 0.38$ & 0.057 & 0.356 & 4.39 & 0.000 & Level of Resillience $\mathrm{R}^{2}=0.23$ \\
\hline Impatience & -0.218 & $-0.03 ;-0.13$ & 0.060 & -0.30 & -4.46 & 0.003 & Level of Confidence \\
\hline Life-work balance Coping & 0.197 & $0.06 ; 0.31$ & 0.065 & 0.209 & 2.83 & 0.001 & $\mathrm{R}^{2}=0.22$ \\
\hline Life-work balance Coping & 0.284 & $0.12 ; 0.45$ & 0.085 & 0.259 & 3.34 & 0.001 & Physical symptoms $\mathrm{R}^{2}=0.14$ \\
\hline Control & 0.337 & $0.17 ; 0.51$ & 0.085 & 0.265 & 3.948 & 0.007 & Energy Level \\
\hline Life-work balance Coping & 0.478 & $0.29 ; 0.66$ & 0.093 & 0.374 & 5.134 & 0.000 & $\mathrm{R}^{2}=0.24$ \\
\hline
\end{tabular}

$\beta=$ Standardized coefficients; ${ }^{* *} \mathrm{p}<0.007$ (with Bronferonni adjustment).

demonstrated consistent highest scores suggesting high stress. The first group, the Occupational therapist social-worker and counsellor group reported highest pressure from recognition, personal responsibility and managerial role, whilst the second group, i.e. the radiographers (RG-RT) reported highest pressure from organisational climate and daily hassles. The OSC group showed high rating for personal-control $(16.3, p=0.001)$ and personal-influence, and the RG-RT group showed high reliance on life-work balance coping. The OSC group are younger in the history of the Malaysian Health care delivery system and it also has the lowest number of personnel. This scenario of a bottle neck situation in terms of lack of job promotion, where only an overwhelmingly few can attain the higher grade suggest a lack of career advancement which may contribute to the pattern of unfavourable individual differences found in this cohort. With two-thirds of Malaysian civil servants being women [14], and as the number of female workers is still on the rise, the organisation must look at ways to advance the career of the female workers, and minimise stress from this source.

Overall, the profile of group individual-differences are characterised by low drive and high impatience. These individual differences suggest a type-A disposition of high impatience which aggravates work stress and a low drive which promotes burnt out [15]. Hostility, a trait of type A, has been linked to coronary heart disease [16], whilst individual differences relating to coping (or use of emotional, cognitive, and/or behavioural strategies to manage one's stress) can reduce harmful impact on psychological adjustment $[8,17,18]$. Research evidence showed that high levels of satisfaction, commitment, security (reflecting high control and influence) were negatively correlated with high pressure and the impatience dimension of Type A [12]. A low job-control has been demonstrated by Karasek (1985) to cause pressure at work and contributes to low mental well-being. Thus, it would augur well for health organisations to consider organizational strategies that can provide more job control and personal influence to these mid-level health professionals whose professional autonomy seems violated within the medical model delivery in Asia.

In this study, three general coping types-problem focus, life-work balance and social support were studied here. Specific coping strategies such as problem-focused coping or emotion-focused coping have been used to facilitate lifestyle practices of stress management $[19,20]$. It has been found that the use of coping strategies is influenced by personality [21], and also by the type of en- 
vironment [22]. This study found that the female professionals rely a lot on life-work balance coping which has a significant positive relationship with four out of the nine outcomes of work pressure.

This study found that women professionals with low confidence, low resilience and low energy level are inclined to resort to high social support strategy. Studies have showed that in self perceived stress is an indicator of psychosocial impairment at the workplace [7]. Also, in times of stress, women tend and befriend rather than fight or flight [23], whereby the use of social support is a critical coping resource for women [24]. Evidence suggest that social support with qualities of hardiness (commitment and control) can moderate the relationship between stress and depression [25]. Drawing from recent finding on women and stress, researchers suggest that women displayed a "tend and befriend" rather than "fight-or-flight" behaviour [26,27]. This finding have implications on intervention program to ensure that skills on getting support and maintaining support should be incorporated into the stress management program particularly for women with low confidence, low resilience and low energy level. A strategy to increase organisational commitments is to improve the personal influence of these women health professionals; whilst to increase organisational satisfaction, organisational security and energy levels, women perceived themselves as having high job control over their work do perform better.

There is an unfavourable pattern of individual differences (characterized by low-drive or low desires to succeed and achieve results), and this does not augur well for the occupational performance of the workers nor of the hospital organization. Job reorganizations involving increasing employee influence and increased job-control were less frequently practice for women and older workers [28], but may be so pertinent in Asian health care organisations, a sector largely led by male medical clinicians who are predominantly, the hierarchical and autocratic decision makers.

Lastly, this paper raises other interesting questions regarding items of stress response, such as social support which showed a tendency towards significance item pressure for four outcomes of pressure. The critical query remains, do women fair better with social support because of the tend-and-befriend stress response [23], since it has a negative relationship to four of the outcomes of pressure. As more and more women today need to balance home and work roles, rehabilitation strategies should be put in place to ameliorate women stressed at work, and to identify which subgroup are most vulnerable in order to provide preventive strategies? The finding support the view that individual differences play a role in the function of job control [28,29], although the role of self efficacy and its relationship to the de- mands-control model needs to be further studied. Future studies should look at comparison with males staff even thought there are relatively fewer males in this mid management jobs. It would also be interesting to do multisite studies on various hospitals to determine if stress is significantly different.

\section{CONCLUSION}

Occupational pressure may be a characteristic burden in the middle management positions that needs to incorporate strategies directed at individuals, or at the organisation as a whole. Individual differences (particularly the level of perceived job-control) and the use of coping strategies (particularly life-work balance) were significant items of occupational pressure of female health professionals. The findings suggest that individual difference act as key correlate to work pressure, with an unfavourable pattern of individual-differences found in these middle management health professionals. Regular audit of Occupational Pressure should be set up so that any evaluation can be carried out immediately or annually for detecting, monitoring and intervening occupational pressure of these middle management health workers. A comprehensive understanding of the transactional process of stress is needed to understand the specific pressure of female health employees within the healthcare delivery system, in order to implement userfriendly policy to enhance occupational and organisational performance and wellbeing at work

\section{REFERENCES}

[1] Vaez, M., Rylander, G., Nygren, A., Asberg, M. and Alexanderson, K. (2007) Sickness absence and disability pension in a cohort of employees initially on long-term sick leave due to psychiatric disorders in Sweden. Social Psychiatry and Psychiatric Epidemiology, 42, 381-388. http://dx.doi.org/10.1007/s00127-007-0189-9

[2] Tennant, C. (2001) Work-related stress and depressive disorders. Journal of Psychosomatic Research, 51, 697704. http://dx.doi.org/10.1016/S0022-3999(01)00255-0

[3] Bartolomucci, A. and Leopardi, R. (2009) Stress and depression: Preclinical research and clinical implications. PLOS ONE, 4, e4265.

http://dx.doi.org/10.1371/journal.pone.0004265

[4] WHO (2005) Preventing chronic diseases: A vital investment. World Health Organisation, Geneva.

http://www.who.int/chp/chronic_disease_report/full_repo rt.pdf;

[5] Mathers, C. and Loncar, D. (2006) Projections of global mortality and burden of disease from 2002 to 2030. PLoS Medicine, 3, 2011-2030. http://dx.doi.org/10.1371/journal.pmed.0030442

[6] Lu, L., Cooper, C., Kao, S. and Zhou, Y. (2003) Work stress, control beliefs and well-being in Greater China- 
An exploration of sub-cultural differences between the PRC and Taiwan. Journal of Managerial Psychology, 18, 479-510. http://dx.doi.org/10.1108/02683940310494359

[7] Limm, H., Angerer, P., Heinmueller, M., Marten-Mittag, B., Nater, U. and Guendel, H. (2010) Self-perceived stress reactivity is an indicator of psychosocial impairment at the workplace. BMC Public Health, 10, 252.

[8] Lazarus, R.S. and Cohen, J.B. (1977) Environmental stress. Plenum, New York.

[9] Fotinatos-Ventouratos, R. and Cooper, C. (2005) The role of gender and social class in work stress. Journal of Managerial Psychology, 20, 14-23.

http://dx.doi.org/10.1108/02683940510571612

[10] Rydmark, I., Wahlberg, K., Ghatan, P., Modell, S., Nygren, A., et al. (2006) Neuroendocrine, cognitive and structural imaging characteristics of women on longterm sickleave with job stress-induced depression. Biological Psychiatry, 60, 867-873. http://dx.doi.org/10.1016/j.biopsych.2006.04.029

[11] Comish, R., Daboval, J. and Swindle, B. (1994) Managing stress in the workplace. The National Public Accountant, 39, 24-27.

[12] William, S. and Cooper, C. (1998) Measuring occupational pressure: Development of the pressure management indicator. Journal of Occupational Health Psychology, 3, 306-321. http://dx.doi.org/10.1037/1076-8998.3.4.306

[13] Loh, S.Y. (2004) Reliability and validity of the pressure management inventory in a Malaysian population. Medical Journal Malaysia, 59, 199.

[14] Singh, S. (1999) Women power rising in civil service. New Straits Time, Malaysia. NST Press, Kuala Lumpur, 1.

[15] Keinan, G. and Melamed, S. (1987) Personality characteristics and proneness to burnout: A study among internists. Stress Medicine, 3, 307-315.

http://dx.doi.org/10.1002/smi.2460030412

[16] Roseman, R. (1978) The interview method of assessment of the coronary-prone behavior pattern. Springer-Verlag, New York.

[17] Lazarus, R. (1993) Coping theory and research: Past, present, and future. Psychosomatic Medicine, 55, 234-247.

[18] Lazarus, R. (2000) Toward better research on stress and coping. American Psychologist, 55, 665-673. http://dx.doi.org/10.1037/0003-066X.55.6.665

[19] Glanz, K., Rimer, B. and Sharyn, S. (2005) Theory at a glance: A guide for health promotion practice. 2nd Edition, United States National Cancer Institute, New York.

[20] Glanz, K., Rimer, B. and Lewis, F. (2002) Health behavior and health education. Theory, research and practice. Wiley \& Sons, San Fransisco.

[21] Bolger, N. (1990) Coping as a personality process: A prospective study. Journal of Personality and Social Psychology, 59, 525-537. http://dx.doi.org/10.1037/0022-3514.59.3.525

[22] Mattlin, J., Wethington, E. and Kessler, R.C. (1990) Situational determinants of coping and coping effectiveness. Journal of Health and Social Behavior, 31, 103-122. http://dx.doi.org/10.2307/2137048

[23] Taylor, S.E., Klein, L.C., Lewis, B.P., Gruenewald, T.L., Gurung, R. and Updegraff, J. (2000) Biobehavioral responses to stress in females: Tend-and-befriend, not fightor-flight. Psychological Review, 107, 411-429. http://dx.doi.org/10.1037/0033-295X.107.3.411

[24] Greenglass, E. (2002) Work stress, coping and social support: Implications for women's occupational well-being. APA, Washington DC, 85-96.

[25] Pengilly, J. and Dowd, E. (2000) Hardiness and social support as moderators of stress. Journal of Clinical Psychology, 56, 813-820 http://dx.doi.org/10.1002/(SICI)1097-4679(200006)56:6< 813::AID-JCLP10>3.0.CO;2-Q

[26] Taylor, S., Klein, L., Lewis, B., Gruenewald, T., Gurung, R. and Updegraff, J. (2000) Biobehavioral responses to stress in females: Tend-and-befriend, not fight-or-flight. Psychological Review, 107, 441-429 http://dx.doi.org/10.1037/0033-295X.107.3.411

[27] Taylor, S., Klein, L., Lewis, B., Gruenewald, T., Gurung, R. and Updegraff, J. (2002) Sex differences in biobehavioral responses to threat: Reply to Geary and Flinn. Psychological Review, 109, 751-753.

[28] Karasek, R. (1990) Lower health risk with increased job control among white collar workers. Journal of Organizational Behavior, 11, 171-185. http://dx.doi.org/10.1002/job.4030110302

[29] Karasek, R. (1979) Job demands, job decision latitude and mental strain. Administrative Science Quarterly, 24, 129-144. http://dx.doi.org/10.2307/2392498

[30] Loh, S.Y. (2004) Reliability and validity of the pressure management inventory in a Malaysian population. Medical Journal of Malaysia, 59, 199-206. 